\section{FACTORS CONCERNED IN FERTILITY OF MAMMALS}

$\mathrm{T}$

HE Society for the Study of Fertility held its second annual Conference on Fertility at Girton College, Cambridge, on June 20 and 21. There were four scientific sessions. The effects of experimental lesions of the hypothalamus in female rats on their cestrous cycles and mating behaviour have been studied by Miss H. M. Bruce and Dr. G. C. Kennedy (National Institute for Medical Research). No specific effects from such experimental lesions were seen on the cycles, whether the operation was followed by the development of obesity or not. However, in those rats which became obese, regardless of whether or no normal cycles continued, mating and pregnancy never occurred. Of ten animals in which obesity did not follow operation, only two mated. All the controls mated. Hypothalamic lesions produced in lactating rats did not always interfere with the continuation of lactation, even though obesity might supervene. The small, discrete, hypothalamic lesions did not result in gonadal atrophy in the rat. So far, only one sex effect could be localized in the hypothalamus, namely, a centre controlling the secretion of luteinizing hormone by the pituitary.

Mr. H. J. Cembrowicz (Ilminster) discussed the fertility-levels of bulls at an artificial insemination centre. Using as an index of conception the nonoccurrence of cestrus in the three months following an insemination, it was found that there had been a rise in the conception-rate from 51 to 69 per cent between 1944 and 1950. During the same period, there had been a nearly five-fold increase in the number of inseminations per year, a six-fold increase in the number of inseminations per bull, and a sevenfold increase in the dilution of the semen used for insemination. Although semen production shows differences between breeds, with improved technique these become much less. Unlike the experience of the Milk Marketing Board, at his centre there has been no fall in conception-rate with increasing age of the bull, even when this reached eight and nine years. In the evaluation of the semen, motility has been found to be the best criterion. With different bulls, from one to three ejaculations per week can be obtained. It was found that 0.5 c.c. of diluted semen is just as effective a dose for insemination as 2 c.c.

Dr. Edmond J. Farris (Wistar Institute, Philadelphia) described his rat ovary hyperæmia test for the prediction of the day of ovulation in humans, and summarized some of the experimental work he has done to confirm its validity. He discussed its value, and the conclusions to be drawn from its use, in the practical handling of human infertility problems.

Dr. Nancy Laughton (University of Birmingham) described the bacteriological findings in cervical swabs taken from two groups of women, one showing positive and the other negative post-coital tests. (This work was done in conjunction with a study, reported by Miss Dorothy N. Shotton (of the Women's Hospital, Birmingham), on the cervical factor in human fertility.) The most striking feature was the absence of pathogenic organisms in all except one case from each of the two groups (this was $B$. coli in both instances). She had isolated from several patients of both groups a hitherto undescribed organism which is a small Gram-positive pleomorphic bacillus, $0 \cdot 7 \mu$ in diameter and $1-3 \mu$ in length. It is culturally delicate and shows a rudimentary branch- ing habit. From its morphology and cultural characteristics, which she detailed, it was concluded that it belongs to the order Actinomycetales. She gave it the provisional name Corynebacterium cervicis.

Experiments on the effect of thyroid hormone and of thiouracil on spermatogenesis in mice, rabbits and rams were described by Dr. M. Maqsood (Cambridge). Thiouracil interferes with the development of the germinal epithelium and decreases the number of interstitial cells. Thyro-protein, on the other hand, speeds up maturation of the testis, so long as the dose remains within the physiological range. In rams, thyroxin-treatment prevents the usual summer decline in spermatogenesis and improves the seminal quality generally. Thyroxin given to rabbits with previously poor records of semen production improves the seminal quality in all cases. Administration for forty-four weeks had no deleterious effect on the testes, whereas administration of thiouracil for a similar period led to complete testicular atrophy.

Dr. B. P. Wiesner and Prof. John Yudkin (King's College of Household and Domestic Science, London) described their experiments on the results of feeding a purified diet containing the known vitamin supplements to rats. They found that the interval from pairing to parturition is, in general, lengthened as compared with that of the controls fed on a stock diet; but most striking was the almost invariable death of the new-born young, in an emaciated condition, within two days of birth. Adding whole liver, and, to a lesser extent, vitamin $\mathbf{B}_{12}$, corrected this effect, but only partially. It seems possible that the necessary nutritional factor (which they call ' $R$ ') may also be present in yeast. A method for the drying of liver at low temperature in vacuo, to produce a stable powder still containing factor $R$, was described.

Dr. T. Mann (Molteno Institute, Cambridge) described chemical methods of use in the analysis of semen. These include the estimation of fructose and citric acid and the demonstration of cytochrome by means of the microspectrometer. $\mathrm{He}$ also directed attention to the recent discovery in his laboratory of the presence of ergothioneine in seminal fluid. $\mathrm{He}$ was followed by Mrs. Clare Harvey (Exeter), who described the results of fructose and citric acid estimations in human semen. There are wide ranges of values for both these constituents, and no clear correlation with other seminal characteristics; though high fertility seems, in general, to be associated with relatively low fructose and high citric acid contents.

Dr. John MacLeod (Cornell University, New York) compared the seminal findings in 1,000 men of proved fertility with those in the husbands of 1,000 infertile marriages. His main conclusions are that sperm density, provided it exceeds 20 millions per ml., is of little significance; but high proportions of motile forms, with vigorous activity, is characteristic of the fertile males. There is no evident association of seminal abnormalities with repeated miscarriages.

Other papers were read by Dr. S. Bender (University of London) on the outcome of pregnancy in women previously sterile; Dr. Raymond G. Cross (Dublin) on tuberculous endometritis; Mr. Donald Young (Warrington) on surgery of the vas deferens; Dr. B. Sandler (Manchester) on the relationship of cervical hostility and asthenozoospermia in human sterility; and Dr. A. C. Crooke (Birmingham) on the effects of various adrenergic and cholinergic drugs on the gonadotrophin excretion of women with amenorrhœa. 